\title{
Amino-Functionalized Reduced Graphene-Oxide-Copper (I) Oxide Composite: A Prospective Catalyst for Photo-Reduction of $\mathrm{CO}_{2}$
}

\author{
Srijita Basumallick \\ Department of Chemistry, National Institute of Technology, Agartala, India \\ Email: srijitabasumallick@gmail.com
}

Received 20 March 2016; accepted 24 April 2016; published 27 April 2016

Copyright (C) 2016 by author and Scientific Research Publishing Inc.

This work is licensed under the Creative Commons Attribution International License (CC BY). http://creativecommons.org/licenses/by/4.0/

(c) (i) Open Access

\begin{abstract}
In the present article, an easy synthetic strategy of a novel composite photo-catalyst comprising of amino-functionalized reduced graphene oxide and $\mathrm{Cu}_{2} \mathrm{O}$ has been proposed. Role of this composite catalyst in photo reduction of $\mathrm{CO}_{2}$ has been analyzed and it is shown that both amino groups and reduced grapheme oxide, participate in enhancing quantum yield of the photo reduction process.
\end{abstract}

\section{Keywords}

\section{Reduced Graphene Oxide, Photo-Catalyst, Cuprous Oxide}

\section{Introduction}

In recent years, Graphene Oxide (GO) and partially reduced Graphene Oxide (rGO) are drawing attention as new generation of catalysts due to their high specific surface area, with unique graphitized basal plane structure having excellent electrical, mechanical and thermal properties [1] [2]. The wettability and accessibility of the substrates over active surface are augmented by occurrence of surface oxides as in case of GO/rGO. This leads to a better dispersion of metal or metal-oxide nanoparticles onto GO/rGO catalyst surface [3] [4].

The presence of residual oxygen groups on reduced graphene oxide (rGO) augments the catalytic activity of rGO [5] [6]. It helps protonation/de-protonation and electronation/de-electronation reactions aided by these functional groups of rGO. Some recent works on nanoparticles-graphene or rGO composites are interesting. Generally, these composites are prepared by co-reduction of graphene oxide and metal precursor salt by chemical method using $\mathrm{NaBH}_{4}$, hydrazine hydrate, ethylene glycol, etc. as reducing agents [7] [8]. Sharma et al. [6] 
synthesized reduced graphene oxide/platinum composite electro catalysts by employing a fast and eco-friendly microwave-assisted poly-ol process. One of the best eco-friendly methods is the electrochemical reduction [9] of graphene oxide to rGO which is a promising and greener way of obtaining rGO. rGO-metal-oxide nano-composites have been reported [10] [11] as efficient photo-catalyst/electro-catalyst for $\mathrm{CO}_{2}$ reduction.

Carbon dioxide is a major product of fossil fuel combustion. With rapid urbanization and industrialization, the increasing trend of atmospheric $\mathrm{CO}_{2}$ is alarming [12]. The natural photo-synthetic path is not enough for restoring $\mathrm{CO}_{2}$ balance. Additional large-scale $\mathrm{CO}_{2}$ reduction paths are to be explored to meet the challenges. In addition, if the reduction products are suitable fuels, those may be used in production of electricity in a fuel cell. Fuel oxidation is a thermodynamically and kinetically favorable reaction. But, reduction of $\mathrm{CO}_{2}$ to fuel is thermodynamically unfavorable and requires solar energy or electrical energy to overcome this thermodynamic barrier. It is also a kinetically difficult reaction because of high activation energies of these reactions. Thus, photo-reduction or electro-reduction of $\mathrm{CO}_{2}$ requires efficient photo-catalysts or electro-catalysts for its conversion to usable fuels. In natural photo-synthetic reaction $\mathrm{CO}_{2}$ reduction occurs at dark phase or in carbon cycle catalyzed by RUBP enzyme. In laboratory conditions, $\mathrm{CO}_{2}$ is reduced onto catalytic surface directly by sun light in the presence of a suitable catalyst. The catalysts used are of the following types: (i) semiconductor metal-oxide catalysts; (ii) metal oxide-organic compound composites like $\mathrm{Cu}$-oxide poly-pyrole; (iii) metal-organic compound complexes; (iv) enzyme catalysts; (v) metal/metal oxide in the presence of organic amines. Although, the first four types of catalysts have been discussed well in different reviews [13], discussions on the amine compound mediated metal, metal-oxide photo-catalysts/electro-catalysts are only limited. Recently, we have reported [13] that nano-sized $\mathrm{Cu}(\mathrm{I})$-oxide coated with depolymerized chitosan is an excellent electro-catalyst and photo-catalyst for $\mathrm{CO}_{2}$ reduction. We have explained [14] [15] the unique role of amino groups in chitosan in the improvement of electro-catalytic efficiency of $\mathrm{Cu}_{2} \mathrm{O}$, proposing its ability to reduce hydrogen evolution reaction. Very recently [16], amino-functionalized $\mathrm{GO}-\mathrm{Cu}_{2} \mathrm{O}$ has been used as a photo-catalyst for photo bleaching of some dyes. Tang et al. [11] reported photo-reduction of $\mathrm{CO}_{2}$ by rGO- $\mathrm{Cu}_{2} \mathrm{O}$ composite. These authors have shown that efficiency of this composite catalyst is enhanced to the extent of six folds compared to the $\mathrm{Cu}_{2} \mathrm{O}$ catalyst and highlighted the positive role of rGO in the photo-reduction process of $\mathrm{CO}_{2}$. But at the same time, they have noted transformation of photo-catalyst to $\mathrm{CuO}$ by photo-oxidation of $\mathrm{Cu}(\mathrm{I})$ to $\mathrm{Cu}(\mathrm{II})$. Photo-oxidation occurs at the hole site of the semi-conductor catalyst. Thus, photo corrosion of $\mathrm{Cu}_{2} \mathrm{O}$ is a major problem and a challenging

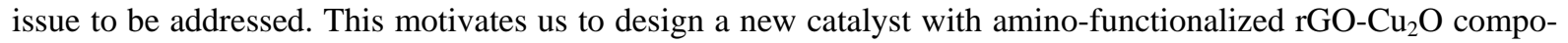
sites, so that amino-groups may be easily oxidised forming unsaturated compounds which may be regenerated protecting photo-corrosion of $\mathrm{Cu}_{2} \mathrm{O}$. To the best of our knowledge there is no report on amino functionalized rGO- $\mathrm{Cu}_{2} \mathrm{O}$ photo-catalyzed $\mathrm{CO}_{2}$ reduction.

\section{Experimental Section}

\section{Preparation of Amino Functionalized Graphene Oxide (G0)}

Graphite oxide is prepared by following Hummer's Method [17]. In a typical protocol, $2 \mathrm{~g}$ of Graphite flakes were mixed with $1.0 \mathrm{~g} \mathrm{NaNO}$ and $50 \mathrm{ml}$ of sulphuric acid in a beaker and stirred vigorously. The mixture was kept at $0^{\circ} \mathrm{C}$ in an ice bath for 5 minutes. To the above mixture, $6 \mathrm{~g} \mathrm{KMnO}_{4}$ is added at small intervals time and reaction temperature is generally kept below $20^{\circ} \mathrm{C}$ during the addition. The temperature is then raised to $30^{\circ} \mathrm{C}$ $35^{\circ} \mathrm{C}$ and maintained for 30 minutes. The mixture gradually became pasty and small amount of gas was evolved. $15 \mathrm{ml}$ of water was added and the temperature was further increased to $98^{\circ} \mathrm{C}$ and stirred for another 15 minutes. $30 \mathrm{ml}$ of water and $2 \mathrm{ml}$ of $30 \% \mathrm{H}_{2} \mathrm{O}_{2}$ are added to ensure reduction of residual permanganate and $\mathrm{MnO}_{2}$ to colorless soluble manganese sulphate. The suspension is filtered and the residue is collected and washed successively with DI water, EtOH and $3 \% \mathrm{HCl}$. It is then dried in a oven kept at $40^{\circ} \mathrm{C}$ for 12 hours.

Graphene oxide (GO) is prepared by suspending 0.020 g graphite oxide in $40 \mathrm{ml}$ DI water and ultrasonicated for 1 hour for exfoliation. The homogeneous mixture is centrifuged at $3000 \mathrm{rpm}$ for 30 minutes to get non-sediment supernatant solution. After decanting the supernatant solution, the residue is washed, dried and characterized.

Graphene oxide $(0.01 \mathrm{~g})$ is taken in a small hydrothermal reactor and mixed with NN dimethyl tetra-ethylene diamine solution and heated for 30 minutes at $800^{\circ} \mathrm{C}$ during this process the amino functionalized GO is obtained by the following reaction.

The amino functionalized GO is then taken in a round bottom flask mixed with $\mathrm{CuSO}_{4}(0.1 \mathrm{M})$ solution and 
$\mathrm{NH}_{2} \mathrm{OH} \cdot \mathrm{HCl}$ is added as a reducing agent, the entire mixture is stirred magnetically at $50^{\circ} \mathrm{C}$ for $2 \mathrm{~h}$, the reaction mixture is cooled to room temperature and centrifuged. The residue is washed with DI water and re-dispersed for photo-reduction of $\mathrm{CO}_{2}$ study. The composite particles so formed have been primarily characterized by UVVisible, SEM and EDX studies.

\section{Result and Discussion}

Preparation of graphite oxide from graphite powder by Hummers method is a conventional protocol for such preparation. But exfoliation of graphite oxide to graphene oxide (GO) depends on sonication conditions. Degree of exfoliation depends on frequency as well as time of exfoliation. It may be mentioned that highly exfoliated sheets may undergo agglomeration forming aggregated colloidal dispersions.

Amino functionalized GO (AGO) is obtained by well reported protocol; however caution has been taken during hydrothermal amino functionalization reaction.

Figure 1(a) shows the UV-visible spectra of very dilute GO dispersions in water, it is seen that GO does not absorb visible light, indicating it is not playing any role at the light absorption stage. But the composite particle absorbs at $635 \mathrm{~nm}$ (Figure 1(b)) owing to the excitation of electrons from valence band of $\mathrm{Cu}_{2} \mathrm{O}$ to its conductance band (band gap energy of $\mathrm{Cu}_{2} \mathrm{O}$ is around $2.0 \mathrm{eV}$ ). This value is close to the reported value [11] of rGO$\mathrm{Cu}_{2} \mathrm{O}$ particles indicating copper is present as $\mathrm{Cu}(\mathrm{I})$.

SEM image of GO is shown in Figure 2(a), which indicates presence of sheet like structure but similar image for the composite particles shows almost spherical particles of average sizes $300 \mathrm{~nm}$. EDX data indicates presence of $\mathrm{C}, \mathrm{O}, \mathrm{N}$ and $\mathrm{Cu}$ in the composite particle.

Since the main propose of this article is to project the role of amino groups and rGO in catalytic reduction of $\mathrm{CO}_{2}$, we propose, a logical scheme (Figure 3) to understand the probable mechanism. The key idea behind such an analysis is that the photo-excited electron from conduction band of $\mathrm{Cu}(\mathrm{I})$-oxide gets easily trapped by rGO [11] and transfer to adsorbed $\mathrm{CO}_{2}$ (as shown in the Figure 3). The holes on the valence band ${ }^{2} \mathrm{Cu}_{2} \mathrm{O}$ will be scavenged [18] by the electrons from the amines attached to rGO. It is well reported amino-compounds act as sacrificial electron donor in photo-catalytic reactions. In doing so, the amino-compounds get oxidized to unsaturated compounds (shown in Figure 3) which are difficult [18] to regenerate in situ. But here photo-generated hydrogen [19] onto rGO surface may regenerate the sacrificed amine simple by chemical reduction. Recently [19], electro-catalytic reduction of $\mathrm{CO}_{2}$ onto $\mathrm{Cu}$ loaded poly-pyrole has been reported, these authors have proposed formation of $\mathrm{H}$ add atom onto poly -pyrole surface, which reduces adsorbed $\mathrm{CO}_{2}$ chemically.

The photo-excited electron transfer from conduction band of $\mathrm{Cu}_{2} \mathrm{O}$ via rGO to adsorbed $\mathrm{CO}_{2}$ is well explained [11]. In fact, electronation of $\mathrm{CO}_{2}$ to $\mathrm{CO}_{2}^{-}$radical anion is difficult, but proton assisted electronation with formation of formic acid $\left[\mathrm{CO}_{2}+2 \mathrm{H}^{+}+2 \mathrm{e}=\mathrm{H}_{2} \mathrm{CO}_{3}\right]$, occurs at much lower potential. But water oxidation reaction on the hole site is extremely difficult [20] relative to hole scavenging by sacrificial amine, hence amino functionalized amine is a better choice.

The scheme will significantly reduce the photo-excited electron-hole recombination reaction, a major pitfall of enhancing quantum yield of photo-chemical process onto semiconductor surfaces. Very recently, possible use of renewable amine in photo-catalytic reduction of $\mathrm{CO}_{2}$ onto Pt has been proposed [18].

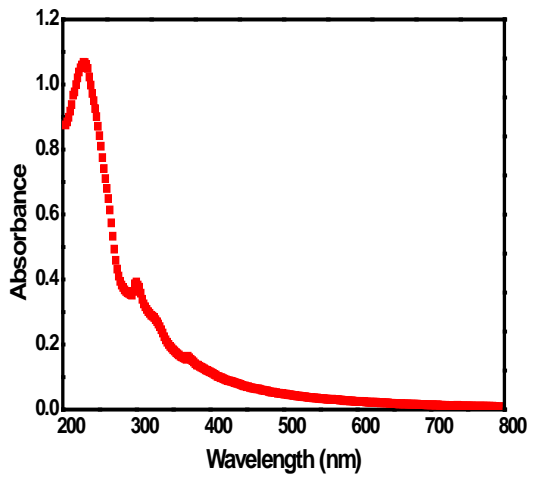

(a)

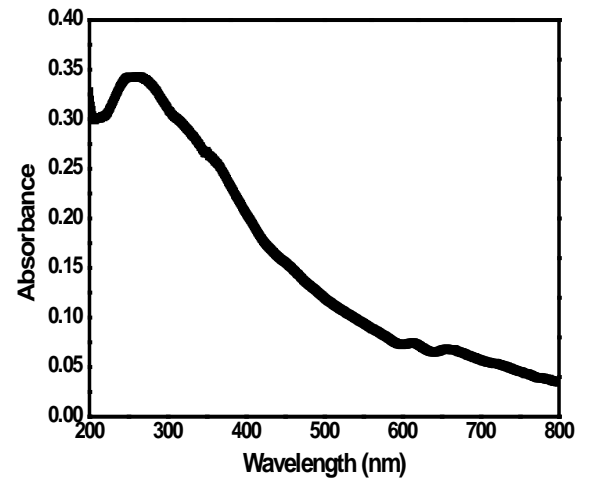

(b)

Figure 1. UV-visible spectra of GO dispersions in water (a) and $\mathrm{Cu}_{2} \mathrm{O}$ composite in water (b). 


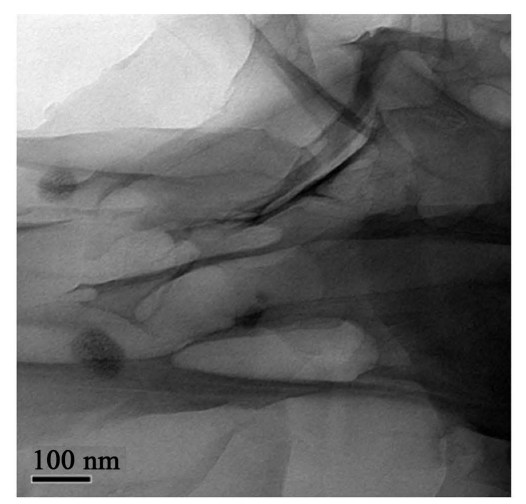

(a)

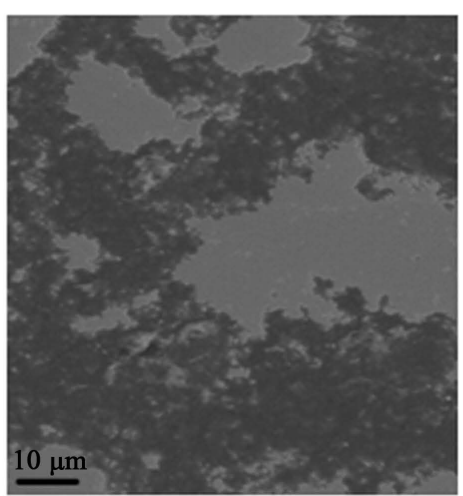

(b)

Figure 2. SEM image of $\mathrm{GO}(\mathrm{a})$ and $\mathrm{Cu}_{2} \mathrm{O}$ composite in water (b).
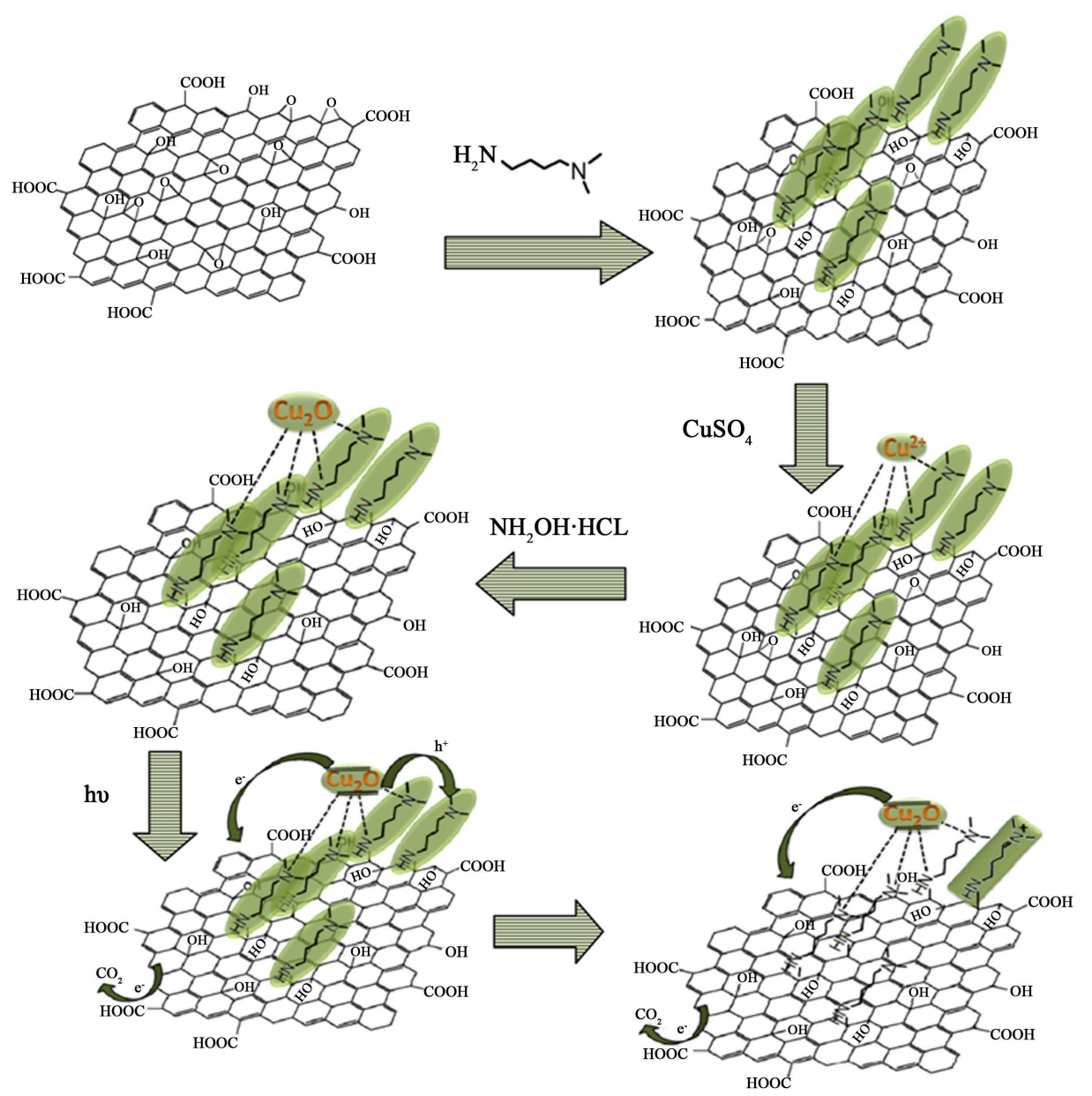

Figure 3. Synthetic scheme of amino-rGO- $\mathrm{Cu}_{2} \mathrm{O}$ composite and their photo-catalytic reaction for $\mathrm{CO}_{2}$ reduction.

It is reported homogeneous catalyst enhances $\mathrm{CO}_{2}$ reduction by forming $\mathrm{CO}_{2}$-catalyst soluble adduct with a less kinetic barrier for electron transfer process. Whereas, it is known heterogeneous catalyst has poor efficiency due to low $\mathrm{CO}_{2}$ adsorption of onto its surfaces. But, presence of amino groups onto catalytic surface, enhance adsorption of $\mathrm{CO}_{2}$. Therefore, proposed combined amine functionalized reduced graphene oxide $\mathrm{Cu}(\mathrm{I})$-oxide composite will serve as an ideal photo-catalyst for $\mathrm{CO}_{2}$ reduction. 


\section{Conclusion}

Based on our primary studies and critical analysis, we have presented for the first time an easy synthetic strategy

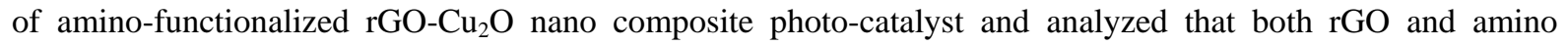
groups play an important role in enhancing quantum yield of photo-catalyzed reduction of $\mathrm{CO}_{2}$. Design of future composite photo-catalysts combing $\mathrm{rGO}, \mathrm{Cu}_{2} \mathrm{O}$ and amino-compounds will certainly help to reduce photo-corrosion of $\mathrm{Cu}_{2} \mathrm{O}$.

\section{Acknowledgements}

SBM is thankful to HOD, Chemistry, NITA for providing with necessary support.

\section{References}

[1] Zhu, Y., Murali, S., Cai, W., Li, X., Suk, J.W., Potts, J.R. and Ruoff, R.S. (2010) Graphene and Graphene Oxide: Synthesis, Properties, and Applications. Advanced Materials, 22, 3906-3924. http://dx.doi.org/10.1002/adma.201001068

[2] Geim, A.K. and Novoselov, K.S. (2007) The Rise of Graphene. Nature Materials, 6, 183-191. http://dx.doi.org/10.1038/nmat1849

[3] Eda, G., Fanchini, G. and Chhowalla, M. (2008) Large-Area Ultrathin Films of Reduced Graphene Oxide as a Transparent and Flexible Electronic Material. Nature Nanotechnology, 3, 270-274. http://dx.doi.org/10.1038/nnano.2008.83

[4] Li, X., Chen, W.X., Zhao, J., Xing, W. and Xu, Z.D. (2005) Microwave Polyol Synthesis of Pt/CNTs Catalysts: Effects of $\mathrm{pH}$ on Particle Size and Electrocatalytic Activity for Methanol Electrooxidization. Carbon, 43, 2168-2174. http://dx.doi.org/10.1016/j.carbon.2005.03.030

[5] Sieben, J.M., Duarte, M.M.E. and Mayer, C.E. (2009) Electro-Oxidation of Methanol on Pt[BOND]Ru Nanostructured Catalysts Electrodeposited onto Electroactivated Carbon Fiber Materials. ChemCatChem, 2, 182-189. http://dx.doi.org/10.1002/cctc.200900223

[6] Sharma, S., Ganguly, A., Papakonstantinou, P., Miao, X., Li, M., Hutchison, J.L., Delichatsios, M. and Ukleja, S. (2010) Rapid Microwave Synthesis of CO Tolerant Reduced Graphene Oxide-Supported Platinum Electrocatalysts for Oxidation of Methanol. The Journal of Physical Chemistry C, 114, 19459-19466. http://dx.doi.org/10.1021/jp107872z

[7] Guo, S., Wen, D., Zhai, Y., Dong, S. and Wang, E. (2010) Platinum Nano Particle Ensemble-On-Graphene Hybrid Nano Sheet: One-Pot, Rapid Synthesis, and Used as New Electrode Material for Electrochemical Sensing. ACS Nano, 4, 3959-3968. http://dx.doi.org/10.1021/nn100852h

[8] Kundu, P., Nethravathi, C., Deshpande, P.A., Rajamathi, M., Madras, G. and Ravishankar, N. (2011) Ultrafast Microwave-Assisted Route to Surfactant-Free Ultrafine Pt Nanoparticles on Graphene: Synergistic Co-Reduction Mechanism and High Catalytic Activity. Chemistry of Materials, 23, 2772-2780. http://dx.doi.org/10.1021/cm200329a

[9] Shao, Y., Wang, J., Engelhard, M., Wanga, C. and Lin, Y. (2010) Facile and Controllable Electrochemical Reduction of Graphene Oxide and Its Applications. Journal of Materials Chemistry, 20, 743-748. http://dx.doi.org/10.1039/B917975E

[10] Hsu, H.C., Shown, I., Wei, H.Y., Chang, Y.C., Du, H.Y., Lin, Y.G., Tseng, C.A., Wang, C.H., Chen, L.C., Lind, Y.C. and Chen, K.H. (2013) Graphene Oxide as a Promising Photocatalyst for $\mathrm{CO}_{2}$ to Methanol Conversion. Nanoscale, 5, 262-268. http://dx.doi.org/10.1039/C2NR31718D

[11] An, X., Li, K. and Tang, J. (2014) $\mathrm{Cu}_{2} \mathrm{O}$ /Reduced Graphene Oxide Composites for the Photocatalytic Conversion of $\mathrm{CO}_{2}$. ChemSusChem, 7, 1086-1093. http://dx.doi.org/10.1002/cssc.201301194

[12] http://www.esrl.noaa.gov/gmd/ccgg/trends/

[13] Wang, W.N., Soulis, J., Yang, Y.J. and Biswas, P. (2014) Comparison of $\mathrm{CO}_{2}$ Photoreduction Systems: A Review. Aerosol and Air Quality Research, 14, 533-549. http://dx.doi.org/10.4209/aaqr.2013.09.0283

[14] Basumallick, S. and Santra, S. (2014) Chitosan Coated Copper-Oxide Nano Particles: A Novel Electro-Catalyst for $\mathrm{CO}_{2}$ Reduction. RSC Advances, 4, 63685-63690. http://dx.doi.org/10.1039/C4RA12696C

[15] Basumallick, S. (2015) Photo-Catalytic Reduction of $\mathrm{CO}_{2}$ to Ethanol. Journal of Advanced Chemical Sciences, 1, 53-55.

[16] Chakravarty, A., Bhowmik, K., Mukherjee, A. and De, G. (2015) $\mathrm{Cu}_{2} \mathrm{O}$ Nanoparticles Anchored on Amine-Functionalized Graphite Nanosheet: A Potential Reusable Catalyst. Langmuir, 31, 5210-5219. http://dx.doi.org/10.1021/acs.langmuir.5b00970

[17] Hummers, W.S. and Ofmann, R.E. (1958) Preparation of Graphitic Oxide. Journal of the American Chemical Society, 80, 1339-1339. http://dx.doi.org/10.1021/ja01539a017 
[18] Richardson, R.D., Holland, E.J. and Carpenter, B.K. (2012) A Renewable Amine for Photochemical Reduction of $\mathrm{CO}_{2}$. Nature Chemistry, 3, 301-303. http://dx.doi.org/10.1038/nchem.1000

[19] Aydına, R., Doğan, H.O. and Köleli, F. (2013) Electrochemical Reduction of Carbondioxide on Polypyrrole Coated Copper Electro-Catalyst under Ambient and High Pressure in Methanol. Applied Catalysis B: Environmental, 140-141, 478-482. http://dx.doi.org/10.1016/j.apcatb.2013.04.021

[20] Lloret-Fillol, J. and Costas, M. (2016) Water Oxidation: High Five Iron. Nature Energy, 1, 16023. http://dx.doi.org/10.1038/nenergy.2016.23 